To cite this article: Moyosore O. Adegboye \& Samuel Adeyoyin (2020) Health Information Resources Accessibility as Predictors for Clinical Decision making among Doctors in Obafemi Awolowo University, Ile-lfe, Nigeria. Information Impact: Journal of Information and Knowledge Management, 11:4, 81-91, DOI: https://dx.doi.org/10.4314/iijikm.v11i4.8

To link to this article: https://dx.doi.org/10.4314/iijikm.v11i4.8

\title{
Health Information Resources Accessibility as Predictors for Clinical Decision Making among Medical Doctors in Obafemi Awolowo University Ile-Ife, Nigeria
}

\author{
${ }^{1}$ Moyosore O. Adegboye \\ ${ }^{1}$ Samuel Adeyoyin \\ ${ }^{1}$ Department of Communication and General Studies, Federal University of Agriculture, Abeokuta, Nigeria
}

\begin{abstract}
The study evaluates health information resources as predictors for clinical decision- making among medical doctors in Obafemi Awolowo University Teaching Hospital Ile-Ife. A survey research design was adopted by the study and random sampling technique was used to select 265 medical doctors from a population of 822. Primary data were obtained on socioeconomic characteristics of the respondents, level of accessibility, frequency and various core skills of health information resources using a structured questionnaire and focus group discussion (FGD). Data were analyzed using frequency counts, percentage and mean. Results revealed that $59.8 \%$ of the respondents were male while $51.1 \%$ were female. Findings, however, showed that pattern recognition from experience $(\bar{x}=3.32)$, critical thinking without emotion ( $\bar{x}=3.16)$, hypothesis updating $(\bar{x}=3.607)$ and perception based confidence $(\bar{x}=2.97)$ were the core skills used by the medical doctors in clinical decision making. The focus group discussion emphasized that medical doctors should possess critical thinking without emotions and good time pressure balance in order to make accurate clinical decisions. The study concludes that medical doctors have quality access to health information resources to make clinical decisions. The study, therefore recommended regular trainings of medical personnel on health information resources to ensure accurate and sound decision making in order to enhance optimal performance.
\end{abstract}

Keywords Information sharing, Job satisfaction, Librarians, Private Universities

CONTACT Moyosore O.Adegboye, and Samuel Adeyoyin adegboyemoyo@gmail.com Department of Communication and General Studies, Federal University of Agriculture, Abeokuta, Nigeria. 


\section{Introduction}

It is common knowledge that during patient consultations, primary care medical doctors need patientspecific information. Accessing information in a timely manner is essential for the clinical decision-making process. Information needs remain unanswered at the time the medical doctors are making clinical decisions, then delayed or uninformed decisions might occur. Consequently, there may be medical errors such as incorrect diagnosis, error in administering treatment or failure to provide prophylactic treatment which impacts the quality and outcome of decisions. Information needs of medical doctors are defined as expressions of missing information that is required to accomplish a specific task, which in this case is managing patient care (Van Osch, Wakker, Van den Hout, \&Stiggelbout, 2008).

Medical doctors are generally involved in the activities that are geared towards the provision of health services including diagnosing, maintaining, or treating the patient's physical or mental condition, with the support of other of health workers. The activities that fall within health work in the context of this study include and not limited to administering a drug or other substance, chemotherapy; physical examination of a patient; dental or oral health examinations and treatment; psychological assessment; interventions such as blood and blood product transfusions; invasive procedures, surgical operations, oral health interventions; pathological and radiological investigations or procedures, for example, taking a blood sample or biopsy for analysis; manipulation ; screening undertaken for pathological conditions, for example, breast or bowel cancer; services provided by the allied health disciplines such as the application of splints or heat packs; the transfer of a patient to another facility; and clinical trials or medical research (Sketcher-Baker, 2017).

Hossain and Shin ( 2012) admit that access to accurate medical information, in various health care facilities, is very necessary for medical doctors to take effective medical decision. Attama and Ezema, (2005) argue that access and use of information are necessary for medical doctors for problem solving and decision making. Other skills required for effective clinical decision making as reported by Nuq (2012) are teamwork, using the gathered evidence to enlist help, support and advice from colleagues and the wider multi-disciplinary team. It is important to liaise with colleagues, listen and be respectful, whilst also being persistent when one needs support so that one can plan as a team when necessary; Sharing learning and getting feedback from colleagues on your decision making; reflection; using feedback from others, and the outcomes of the decisions to reflect on the decisions that were taken in order to enhance practice delivery in the future. It is also important for medical doctors to reflect on their whole decision-making strategies to ensure that they hone their decision-making skills and learn from experience. Health Information accessibility refers to the ease with which medical doctors acquire the right information from available sources to solve the problems encountered during clinical decision making (Kahane, 2011). Accessibility to health information is seen in relation to nearness, ease of use and opportunities for interaction with people and other agencies while proximity and physical distance to a source or channel have been found to be factors influencing use of information. Aguolu and Aguolu (2002) reveal that efforts are being made worldwide to promote access to information. They however lament the attendant features of underdevelopment such as power failure, machine breakdowns, and lack of spare parts and technicians, which intermittently stall the performance of modern gadgets of information storage and transfer in developing countries.

Oltman (2009) in his study provided an early example of the difficulties in articulating information accessibility. He identifies six components of information access, which are identification, availability, price (to the users), cost (to the provider), understanding (awareness), and acceptability. Similarly, Gans, Kralweki, Hammons and Dowd (2005) presented four elements of information accessibility, which are channel, nearness, and cost and literacy level. Yogarajan, Mayo and Pfahringer (2018) opined that an information channel serves as an intermediary, which guides or is supposed to guide an individual to a source. Channels/sources of information such as personal (colleagues and experts), impersonals (newspaper, registers and other print materials) do not exclude the individual and technical communication 
media such as telephone, radio, video and internet. Gans, Kralweki, Hammons and Dowd (2005) affirmed that channel of information involves the interchange of facts and thoughts. Information must be transmitted by means of communication process before it can be accessed or used. Information nearness refers to the short distance or interval in information sources, which constitute an important factor for its accessibility. It explains the closeness of relationship between the source and information users (Davies, 2007). Gatero (2010) also asserts that, information nearness is the distance or intensity and frequency of information interaction between the sources and the users. Thus, distance of information for a given source varies and is infinite (Choudhry, Fletcher \&Soumerai, 2005). When nearness is defined in terms of zero distance within the information and farness in terms of infinite distance outside it, what the users have left is a shift from proximity to access information. Basically, nearness in information is constituted on the basis of users recognising other sources that users can only acknowledge and access other sources of information when it is nearer than other sources. Information however is nearness to anybody in need of it due to technology and worldwide information for all project which aims at eliminating all the barriers to information accessibility. The peculiar condition of health condition may deprive patients' access to some sources of information for the purpose of health condition while health authority needs to establish and meticulously guide some sources of information for security purposes.

Cost of information has been identified as one of the major factors that hindered users' access to information (Panahi, 2014). The cost of information before a user can obtain access varies depending on the source the information emerges from. For instance, some information sources are confidential and cost implication of accessing such information may influence the user to seek such information further. Chinnock, Nandi \& Clarke (2005) also buttressed this assertion that high logistical cost of moving to the location where the information is situated is another crucial factor that determines information accessibility. There are several costs for users in obtaining access to information. These create more obstacles to information accessibility by the patients.T he literacy level of information users rely on users' ability to function in a particular context that requires some background knowledge about information. Jacobs, Amuta and Jeon (2017) conclude that literacy level affects the attitudinal and behavioural patterns of individuals. This implies that users with high literacy level can read, understand and act on any information obtained while users with limited literacy skills are likely to have problems in interpreting the contents of information materials. Watts \&Ibegbulam, 2006). Aspinall, Good, Glassman and Valentino (2008) conclude that literacy includes not only the ability to read, but the complexity of information understood, accessed and acted upon. The means of access to information is a powerful procedural measure, which medical doctors needs to establish and meticulously guided for security purposes. This is so because using and retaining only one means of access to information can have a detrimental effect on the quality of information accessed and this quality has a direct bearing on the information to be accessed and likewise on the clinical decision making. The term empowerment connotes or could mean the process of obtaining basic opportunities for marginalized people, either directly by those people, or through the help of nonmarginalized concerned people who share their own access to these process (Afolayan \& Oyekunle, 2014). However, experts have identified various obstacles to information access. (Panahi, 2014) identified four obstacles to information access: economic, social, environmental, and infrastructure. This study will discuss obstacles in the following areas: Social obstacle and non-availability of information. Social obstacle to patients information seeking and use may hinder the accessibility of health information. A successful accessibility of information depends upon the availability of information and level of accessibility. Information should not be based on their level of availability but easy accessibility; it must be physically accessible to those who need them. Accessibility of health information has turned attention to the problems faced by patients. Effective clinical decision making depends on information access infrastructure facilities like information technology, internet facilities, uninterrupted power supply, high literacy level that will facilitate easy access. 


\section{Statement of the problem}

Despite the fact that there is a high growth rate in human resources capital in every industry and organization globally, there is scarcity of literature devoted to studying the effect of the influence of access and use of health information resources on clinical decision making among medical doctors in OAUTH. Accessing information in a timely way is essential for the clinical decision-making process. If information needs remain unanswered at the time the medical doctors are making clinical decisions, then delayed or uninformed decisions might occur. Consequently, there may be medical errors such as incorrect diagnosis, error in administering treatment or failure to provide prophylactic treatment, which impacts the quality and outcome of decisions. Clinical decision making is a balance of experience, awareness, knowledge and information gathering, using appropriate assessment tools, colleagues and evidence-based practice to guide. Various literatures studied have been able to address the issues facing organizations within a global perspective, and to deal effectively with increased competitive pressure globalization and demand for efficiency within organization, the various medical industries understudied have come to rely on the strategy of restructuring the medical industry and the influence of access and use of health information resources on clinical decision making among medical doctors can be realistic.

Also, in our today's society, information resources are used by medical doctors to complement their knowledge and clinical experience and to keep themselves up to date. However, the Nigerian medical industry is currently experiencing lingering distress, restructuring strategies deficiency; doctors' low performance and turbulence occasioned by globalization in information and decision making, the efficacy and indispensable role of information accessibility by actively engaged medical doctors for clinical decision-making cannot be over emphasized. The relationship between the accessibility, different sources and the decisions to which such information is applied as well as the relationship that exist between the decisions that medical doctors make and the knowledge that informs them are worth given attention, hence this study.

\section{Objectives of the study}

The objectives of this study are to:

- Identify various health information resources accessible for clinical decision making among medical doctors in OAUTH.

- Determine the level of accessibility of health information resources for clinical decision making among medical doctors in OAUTH.

- Examine the frequency of accessibility of health information resources for clinical decision making among medical doctors in OAUTH.

- investigate the extent of use of various core skills of clinical decision making among medical doctors in OAUTH

\section{Research questions}

The following research questions were raised for the study:

- What are the health information resources accessible for clinical decision making among medical doctors in ObafemiAwolowo University Teaching Hospital (OAUTH), Ile-Ife, Osun State, Nigeria?

- What is the level of accessibility of health information resources for clinical decision making among medical doctorsin OAUTH?

- What is the frequency of accessibility to health information resources for clinical decision making among medical doctorsin OAUTH? 
- What is the extent of use of various core skills of clinical decision making among medical doctorsof OAUTH

\section{Methodology}

The study used descriptive research design of correlational type. Descriptive research design is a scientific method which involves observing and describing the behaviour of a subject without moderating it in any way. This method was adopted because it allows the study of a large population in which the perception and feelings of the subjects are easily expressed. The choice of this research design was considered most appropriate for this study because it sought to enhance the understanding of the situation on ground in terms of the influence of the independent on dependent variable studied. The total population was eight hundred and twenty-two (822) medical doctors of various professional status in Obafemi Awolowo University Teaching Hospital (OAUTH), Ile-Ife, Osun State, Nigeria. The categories of medical doctors that were selected for the study were Consultants, Senior Registrars, Registrars, Medical Officers and House Officers. A random sampling technique was used to draw a sample size of 265 using Krejcie and Morgan's (1970) table of sample size under confidence $=95 \%$. Margin of error $=0.05 \%$. Hence, a total number of two hundred and sixty five (265) medical doctors were be used as sample size. Both quantitative and qualitative data were gathered for the study using a set of questionnaires and complemented with a focus group discussion (FGD). Ethical clearance was required in order to gain permission to administer the questionnaire on the medical doctors of the OAUTH. Focus group discussion (FGD) was also held among the two groups of medical doctors with four members in each group totaling eight participants. Out of the 265 sets of questionnaires that were distributed to the respondents in OAUTH, 259 (97.7\%) were duly filled and returned. Focus group discussion was done among the doctors. The descriptive method of data analysis, including frequencies, statistical mean and standard deviation were used.

\section{Data Presentation and Analyses}

Table 1: Various health information resources accessible for clinical decision making among medical doctors in OAUTH

\begin{tabular}{|c|c|c|c|c|c|c|c|}
\hline $\mathbf{S} / \mathbf{N}$ & $\begin{array}{l}\text { Access to health information } \\
\text { resources }\end{array}$ & HA & MA & RA & NA & $\overline{\mathbf{X}}$ & S.D \\
\hline 1 & CT Scan & $\begin{array}{l}144 \\
55.6 \%\end{array}$ & $\begin{array}{l}97 \\
37.5 \%\end{array}$ & $\begin{array}{ll}18 \\
6.9 \%\end{array}$ & - & 3.49 & 0.62 \\
\hline 2 & ECG machine & $\begin{array}{l}133 \\
51.4 \%\end{array}$ & $\begin{array}{l}102 \\
39.4 \%\end{array}$ & $\begin{array}{l}19 \\
7.3 \% \\
\end{array}$ & $\begin{array}{l}5 \\
1.9 \% \\
\end{array}$ & 3.40 & 0.71 \\
\hline 3 & Incubator & $\begin{array}{l}97 \\
37.5 \%\end{array}$ & $\begin{array}{l}116 \\
44.8 \%\end{array}$ & $\begin{array}{l}31 \\
12.0 \%\end{array}$ & $\begin{array}{l}15 \\
5.8 \%\end{array}$ & 3.15 & 0.88 \\
\hline 4 & Orthoscopic & $\begin{array}{l}87 \\
33.6 \%\end{array}$ & $\begin{array}{l}131 \\
50.6 \%\end{array}$ & $\begin{array}{l}33 \\
12.7 \%\end{array}$ & $\begin{array}{l}8 \\
3.1 \%\end{array}$ & 3.15 & 0.75 \\
\hline 5 & Radiograph & $\begin{array}{l}123 \\
47.5 \%\end{array}$ & $\begin{array}{l}71 \\
27.4 \%\end{array}$ & $\begin{array}{l}41 \\
15.8 \%\end{array}$ & $\begin{array}{ll}24 \\
9.3 \%\end{array}$ & 3.13 & 1.00 \\
\hline 6 & GSM phones, I pad, I pod & $\begin{array}{l}110 \\
42.5 \%\end{array}$ & $\begin{array}{l}93 \\
35.9 \% \\
\end{array}$ & $\begin{array}{l}32 \\
12.4 \%\end{array}$ & $\begin{array}{l}24 \\
9.3 \% \\
\end{array}$ & 3.12 & 0.95 \\
\hline 7 & Microscope & $\begin{array}{l}103 \\
39.8 \%\end{array}$ & $\begin{array}{l}99 \\
38.2 \%\end{array}$ & $\begin{array}{l}33 \\
12.7 \%\end{array}$ & $\begin{array}{l}24 \\
9.3 \%\end{array}$ & 3.08 & 0.94 \\
\hline 8 & Computer system & $\begin{array}{l}98 \\
37.8 \%\end{array}$ & $\begin{array}{l}103 \\
39.8 \%\end{array}$ & $\begin{array}{l}37 \\
14.3 \%\end{array}$ & $\begin{array}{l}21 \\
8.1 \%\end{array}$ & 3.07 & 0.92 \\
\hline 9 & Telemedicine & $\begin{array}{l}98 \\
37.8 \%\end{array}$ & $\begin{array}{l}106 \\
40.9 \%\end{array}$ & $\begin{array}{ll}22 \\
8.5 \%\end{array}$ & $\begin{array}{ll}33 \\
12.7 \%\end{array}$ & 3.04 & 0.99 \\
\hline 10 & Electronic BP Gauge & $\begin{array}{l}96 \\
37.1 \%\end{array}$ & $\begin{array}{l}104 \\
40.2 \%\end{array}$ & $\begin{array}{l}30 \\
11.6 \%\end{array}$ & $\begin{array}{l}29 \\
11.2 \%\end{array}$ & 3.03 & 0.97 \\
\hline 11 & Autoclave & $\begin{array}{l}79 \\
30.5 \%\end{array}$ & $\begin{array}{l}116 \\
44.8 \%\end{array}$ & $\begin{array}{l}51 \\
19.7 \%\end{array}$ & $\begin{array}{c}13 \\
5.0 \%\end{array}$ & 3.01 & 0.84 \\
\hline 12 & Internet & $\begin{array}{l}91 \\
35.1 \%\end{array}$ & $\begin{array}{l}106 \\
40.9 \%\end{array}$ & $\begin{array}{l}32 \\
12.4 \%\end{array}$ & $\begin{array}{l}30 \\
11.6 \%\end{array}$ & 3.00 & 0.97 \\
\hline 13 & CD ROM & $\begin{array}{l}92 \\
35.5 \%\end{array}$ & $\begin{array}{l}104 \\
40.2 \%\end{array}$ & $\begin{array}{l}35 \\
13.5 \%\end{array}$ & $\begin{array}{c}28 \\
10.8 \%\end{array}$ & 3.00 & 0.96 \\
\hline
\end{tabular}




\begin{tabular}{|l|l|l|l|l|l|l|l|}
\hline 14 & DVD & 89 & 104 & 42 & 24 & 3.00 & 0.94 \\
& & $34.4 \%$ & $40.2 \%$ & $16.2 \%$ & $9.3 \%$ & & \\
\hline 15 & Glucometer & 86 & 110 & 39 & 24 & 3.00 & 0.93 \\
& & $33.2 \%$ & $42.5 \%$ & $15.1 \%$ & $9.3 \%$ & & \\
\hline 16 & Sphygmomanometer & 74 & 125 & 44 & 16 & 2.99 & 0.84 \\
& & $28.6 \%$ & $48.3 \%$ & $17.0 \%$ & $6.2 \%$ & & \\
\hline 17 & Videoconferencing & 86 & 106 & 42 & 25 & 2.98 & 0.94 \\
& & $33.2 \%$ & $40.9 \%$ & $16.2 \%$ & $9.7 \%$ & & \\
\hline 18 & Hemoglobin electrophoresis & 86 & 101 & 48 & 24 & 2.96 & 0.94 \\
& & $33.2 \%$ & $39.0 \%$ & $18.5 \%$ & $9.3 \%$ & & \\
\hline 19 & Video & 85 & 103 & 45 & 26 & 2.95 & 0.95 \\
& & $32.8 \%$ & $39.8 \%$ & $17.4 \%$ & $10.0 \%$ & & \\
\hline 20 & VCD & 81 & 106 & 48 & 24 & 2.94 & 0.93 \\
& & $31.3 \%$ & $40.9 \%$ & $18.5 \%$ & $9.3 \%$ & & \\
\hline 21 & Projectors & 81 & 105 & 44 & 29 & 2.92 & 0.96 \\
& & $31.3 \%$ & $40.5 \%$ & $17.0 \%$ & $11.2 \%$ & & \\
\hline 22 & Teleconferencing & 77 & 109 & 45 & 28 & 2.91 & 0.95 \\
& & $29.7 \%$ & $42.1 \%$ & $17.4 \%$ & $10.8 \%$ & & \\
\hline
\end{tabular}

KEY: HA=Highly Accessible, MA=Moderately Accessible, RA= Rarely Accessible, NH=Not Accessible

Table 1 shows that CT Scan $(\bar{x}=3.49)$ ranked highest by the mean score rating and was followed in succession by ECG machine $(\bar{x}=3.40)$, Incubator $(\bar{x}=3.15)$ and Orthoscopic $(\bar{x}=3.15)$. This implies that CT Scan, ECG machine, incubator, Orthoscopic, Radiograph, GSM phones, i pad, i pod, microscope and computer system were the major health information resources accessible for clinical decision making among medical doctors in OAUTH. The reason for this is because these were the items that ranked above the weighted mean of 3.05 set as the benchmark.

Table 2:The level of accessibility of health information resources for clinical decision making among medical doctors in OAUTH

\begin{tabular}{|l|l|l|l|l|l|l|l|}
\hline S/N & Health Information resources & HA & MA & RA & NA & $\bar{x}$ & S.D \\
\hline 1 & ECG machine & 140 & 99 & 15 & 5 & 3.44 & 0.69 \\
& & $54.1 \%$ & $38.2 \%$ & $5.8 \%$ & $1.9 \%$ & & \\
\hline 2 & CT Scan & 78 & 167 & 8 & 6 & 3.22 & 0.61 \\
& & $30.1 \%$ & $64.5 \%$ & $3.1 \%$ & $2.3 \%$ & & \\
\hline 3 & GSM phones,I pad, I pod & 99 & 108 & 25 & 27 & 3.08 & 0.95 \\
& & $38.2 \%$ & $41.7 \%$ & $9.7 \%$ & $10.4 \%$ & & \\
\hline 4 & Autoclave & 92 & 113 & 33 & 21 & 3.07 & 0.90 \\
& & $35.5 \%$ & $43.6 \%$ & $12.7 \%$ & $8.1 \%$ & & \\
\hline 5 & Teleconferencing & 93 & 103 & 45 & 18 & 3.05 & 0.90 \\
& & $35.9 \%$ & $39.8 \%$ & $17.4 \%$ & $6.9 \%$ & & \\
\hline 6 & Internet & 90 & 111 & 35 & 23 & 3.03 & 0.92 \\
& & $34.7 \%$ & $42.9 \%$ & $13.5 \%$ & $8.9 \%$ & & \\
\hline 7 & Hemoglobin electrophoresis & 98 & 100 & 32 & 29 & 3.03 & 0.98 \\
& & $37.8 \%$ & $38.6 \%$ & $12.4 \%$ & $11.2 \%$ & & \\
\hline 8 & Sphygmomanometer & 74 & 136 & 33 & 16 & 3.03 & 0.81 \\
& & $28.6 \%$ & $52.5 \%$ & $12.7 \%$ & $6.2 \%$ & & \\
\hline 9 & VCD & 90 & 107 & 38 & 24 & 3.02 & 0.93 \\
& & $34.7 \%$ & $41.3 \%$ & $14.7 \%$ & $9.3 \%$ & & \\
\hline 10 & Microscope & 38 & 198 & 11 & 12 & 3.01 & 0.61 \\
& & $14.7 \%$ & $76.4 \%$ & $4.2 \%$ & $4.6 \%$ & & 1.00 \\
\hline 11 & DVD & 100 & 88 & 42 & 29 & 3.00 & 1.00 \\
& & $38.6 \%$ & $34.0 \%$ & $16.2 \%$ & $11.2 \%$ & \\
\hline 12 & Orthoscopic & 72 & 136 & 30 & 21 & 3.00 & 0.85 \\
& & $27.8 \%$ & $52.5 \%$ & $11.6 \%$ & $8.1 \%$ & & \\
\hline 13 & CD ROM & 99 & 89 & 37 & 34 & 2.98 & 1.03 \\
& & $38.2 \%$ & $34.4 \%$ & $14.3 \%$ & $13.1 \%$ & & \\
\hline 14 & Glucometer & 80 & 114 & 44 & 21 & 2.98 & 0.90 \\
& & $30.9 \%$ & $44.0 \%$ & $17.0 \%$ & $8.1 \%$ & & \\
\hline
\end{tabular}




\begin{tabular}{|c|c|c|c|c|c|c|c|}
\hline 15 & Centrifuge machine & $\begin{array}{l}73 \\
28.2 \%\end{array}$ & $\begin{array}{l}134 \\
51.7 \%\end{array}$ & $\begin{array}{l}23 \\
8.9 \%\end{array}$ & $\begin{array}{l}29 \\
11.2 \%\end{array}$ & 2.97 & 0.91 \\
\hline 16 & Video & $\begin{array}{l}90 \\
34.7 \%\end{array}$ & $\begin{array}{l}102 \\
39.4 \%\end{array}$ & $\begin{array}{l}30 \\
11.6 \%\end{array}$ & $\begin{array}{l}37 \\
14.3 \%\end{array}$ & 2.95 & 1.02 \\
\hline 17 & Videoconferencing & $\begin{array}{l}82 \\
31.7 \%\end{array}$ & $\begin{array}{l}105 \\
40.5 \%\end{array}$ & $\begin{array}{l}35 \\
13.5 \%\end{array}$ & $\begin{array}{l}37 \\
14.3 \%\end{array}$ & 2.90 & 1.01 \\
\hline 18 & Projectors & $\begin{array}{l}82 \\
31.7 \%\end{array}$ & $\begin{array}{l}98 \\
37.8 \% \\
\end{array}$ & $\begin{array}{l}51 \\
19.7 \% \\
\end{array}$ & $\begin{array}{l}28 \\
10.8 \%\end{array}$ & 2.90 & 0.97 \\
\hline 19 & Computer system & $\begin{array}{l}73 \\
28.2 \%\end{array}$ & $\begin{array}{l}108 \\
41.7 \% \\
\end{array}$ & $\begin{array}{l}52 \\
20.1 \% \\
\end{array}$ & $\begin{array}{l}26 \\
10.0 \%\end{array}$ & 2.88 & 0.93 \\
\hline 20 & Telemedicine & $\begin{array}{l}85 \\
32.8 \%\end{array}$ & $\begin{array}{l}100 \\
38.6 \%\end{array}$ & $\begin{array}{l}33 \\
12.7 \%\end{array}$ & $\begin{array}{l}41 \\
15.8 \%\end{array}$ & 2.88 & 1.04 \\
\hline 21 & Radiograph & $\begin{array}{l}67 \\
25.9 \%\end{array}$ & $\begin{array}{l}82 \\
31.7 \%\end{array}$ & $\begin{array}{l}90 \\
34.7 \%\end{array}$ & $\begin{array}{l}20 \\
7.7 \%\end{array}$ & 2.76 & 0.93 \\
\hline 22 & Electronic BP Gauge & $\begin{array}{l}86 \\
33.2 \% \\
\end{array}$ & $\begin{array}{l}78 \\
30.1 \% \\
\end{array}$ & $\begin{array}{l}30 \\
11.6 \% \\
\end{array}$ & $\begin{array}{l}65 \\
25.1 \% \\
\end{array}$ & 2.71 & 1.17 \\
\hline
\end{tabular}

KEY: HA=Highly Accessible, MA=Moderately Accessible, RA= Rarely Accessible, NH=Not Accessible

Table 2 shows that ECG machine ( $\bar{x}=3.44$ ) ranked highest by the mean score rating and was followed in succession by CT Scan $(\bar{x}=3.22)$, GSM phone, ipad, ipod $(\bar{x}=3.08)$. Radiograph $(\bar{x}=2.76)$. This implies that from this, using the weighted mean of 3.00, was that ECG machine, CT scan, GSM phone ipad, ipod, Autoclave, Teleconferencing, Internet, hemoglobin electrophoresis, Sphygmomanometer, VCD and Microscope were the highly accessible health information resources for clinical decision making among medical doctors in OAUTH..

Table 3: The frequency of accessibility to health information resources for clinical decision making among medical doctors in OAUTH

\begin{tabular}{|c|c|c|c|c|c|c|c|c|}
\hline $\mathbf{S} / \mathbf{N}$ & Health Information resources & Daily & Weekly & Monthly & Occasionally & Never & $\bar{x}$ & S.D \\
\hline 1 & ECG machine & $\begin{array}{l}45 \\
17.4 \%\end{array}$ & $\begin{array}{l}154 \\
59.5 \%\end{array}$ & $\begin{array}{l}41 \\
15.8 \%\end{array}$ & $\begin{array}{l}12 \\
4.6 \%\end{array}$ & $\begin{array}{l}7 \\
2.7 \%\end{array}$ & 3.84 & 0.86 \\
\hline 2 & VCD & $\begin{array}{l}94 \\
36.3 \%\end{array}$ & $\begin{array}{l}86 \\
33.2 \%\end{array}$ & $\begin{array}{l}35 \\
13.5 \%\end{array}$ & $\begin{array}{l}26 \\
10.0 \%\end{array}$ & $\begin{array}{l}18 \\
6.9 \%\end{array}$ & 3.82 & 1.22 \\
\hline 3 & Internet & $\begin{array}{l}84 \\
32.4 \%\end{array}$ & $\begin{array}{l}94 \\
36.3 \%\end{array}$ & $\begin{array}{l}41 \\
15.8 \%\end{array}$ & $\begin{array}{l}22 \\
8.5 \%\end{array}$ & $\begin{array}{l}18 \\
6.9 \%\end{array}$ & 3.79 & 1.19 \\
\hline 4 & Teleconferencing & $\begin{array}{l}103 \\
39.8 \%\end{array}$ & $\begin{array}{l}66 \\
25.5 \%\end{array}$ & $\begin{array}{l}39 \\
15.1 \%\end{array}$ & $\begin{array}{l}31 \\
12.0 \%\end{array}$ & $\begin{array}{l}20 \\
7.7 \% \\
\end{array}$ & 3.78 & 1.30 \\
\hline 5 & Telemedicine & $\begin{array}{l}80 \\
30.9 \%\end{array}$ & $\begin{array}{l}98 \\
37.8 \%\end{array}$ & $\begin{array}{l}36 \\
13.9 \%\end{array}$ & $\begin{array}{l}32 \\
12.4 \%\end{array}$ & $\begin{array}{l}13 \\
5.0 \%\end{array}$ & 3.77 & 1.16 \\
\hline 6 & Hemoglobin electrophoresis & $\begin{array}{l}83 \\
32.0 \%\end{array}$ & $\begin{array}{l}85 \\
32.8 \%\end{array}$ & $\begin{array}{l}46 \\
17.8 \%\end{array}$ & $\begin{array}{l}27 \\
10.4 \%\end{array}$ & $\begin{array}{l}18 \\
6.9 \%\end{array}$ & 3.73 & 1.21 \\
\hline 7 & GSM phones, I pad, I pod & $\begin{array}{l}81 \\
31.3 \%\end{array}$ & $\begin{array}{l}82 \\
31.7 \%\end{array}$ & $\begin{array}{l}53 \\
20.5 \%\end{array}$ & $\begin{array}{l}21 \\
8.1 \%\end{array}$ & $\begin{array}{l}22 \\
8.5 \%\end{array}$ & 3.69 & 1.23 \\
\hline 8 & Projectors & $\begin{array}{l}88 \\
34.0 \%\end{array}$ & $\begin{array}{l}75 \\
29.0 \%\end{array}$ & $\begin{array}{l}41 \\
15.8 \%\end{array}$ & $\begin{array}{l}39 \\
15.1 \%\end{array}$ & $\begin{array}{l}16 \\
6.2 \% \\
\end{array}$ & 3.69 & 1.25 \\
\hline 9 & Videoconferencing & $\begin{array}{l}77 \\
29.7 \%\end{array}$ & $\begin{array}{l}99 \\
38.2 \%\end{array}$ & $\begin{array}{l}28 \\
10.8 \%\end{array}$ & $\begin{array}{l}34 \\
13.1 \%\end{array}$ & $\begin{array}{l}21 \\
8.1 \%\end{array}$ & 3.68 & 1.25 \\
\hline 10 & Incubator & $\begin{array}{l}76 \\
29.3 \%\end{array}$ & $\begin{array}{l}90 \\
34.7 \%\end{array}$ & $\begin{array}{l}42 \\
16.2 \%\end{array}$ & $\begin{array}{l}30 \\
11.6 \%\end{array}$ & $\begin{array}{l}21 \\
8.1 \%\end{array}$ & 3.66 & 1.24 \\
\hline 11 & Video & $\begin{array}{l}68 \\
26.3 \%\end{array}$ & $\begin{array}{l}101 \\
39.0 \%\end{array}$ & $\begin{array}{l}42 \\
16.2 \%\end{array}$ & $\begin{array}{l}26 \\
10.0 \%\end{array}$ & $\begin{array}{l}22 \\
8.5 \%\end{array}$ & 3.64 & 1.21 \\
\hline 12 & DVD & $\begin{array}{l}73 \\
28.2 \%\end{array}$ & $\begin{array}{l}92 \\
35.5 \%\end{array}$ & $\begin{array}{l}42 \\
16.2 \%\end{array}$ & $\begin{array}{l}33 \\
12.7 \%\end{array}$ & $\begin{array}{l}19 \\
7.3 \%\end{array}$ & 3.64 & 1.22 \\
\hline 13 & Autoclave & $\begin{array}{l}61 \\
23.6 \%\end{array}$ & $\begin{array}{l}102 \\
39.4 \%\end{array}$ & $\begin{array}{l}46 \\
17.8 \%\end{array}$ & $\begin{array}{l}35 \\
13.5 \%\end{array}$ & $\begin{array}{l}15 \\
5.8 \%\end{array}$ & 3.61 & 1.15 \\
\hline 14 & CD ROM & $\begin{array}{l}83 \\
32.0 \%\end{array}$ & $\begin{array}{l}68 \\
26.3 \%\end{array}$ & $\begin{array}{l}47 \\
18.1 \%\end{array}$ & $\begin{array}{l}44 \\
17.0 \%\end{array}$ & $\begin{array}{l}17 \\
6.6 \%\end{array}$ & 3.60 & 1.27 \\
\hline 15 & Sphygmomanometer & $\begin{array}{l}51 \\
19.7 \%\end{array}$ & $\begin{array}{l}91 \\
35.1 \%\end{array}$ & $\begin{array}{l}72 \\
27.8 \%\end{array}$ & $\begin{array}{l}31 \\
12.0 \%\end{array}$ & $\begin{array}{l}14 \\
5.4 \%\end{array}$ & 3.52 & 1.10 \\
\hline
\end{tabular}




\begin{tabular}{|l|l|l|l|l|l|l|l|l|}
\hline 16 & CT Scan & 34 & 84 & 119 & 18 & 4 & 3.49 & 0.86 \\
& & $13.1 \%$ & $32.4 \%$ & $45.9 \%$ & $6.9 \%$ & $1.5 \%$ & \\
\hline 17 & Glucometer & 66 & 70 & 68 & 35 & 20 & 3.49 & 1.22 \\
& & $25.5 \%$ & $27.0 \%$ & $26.3 \%$ & $13.5 \%$ & $7.7 \%$ & \\
\hline 18 & Microscope & 57 & 74 & 75 & 36 & 17 & 3.46 & 1.17 \\
& & $22.0 \%$ & $28.6 \%$ & $29.0 \%$ & $13.9 \%$ & $6.6 \%$ & & \\
\hline 19 & Radiograph & 74 & 60 & 43 & 73 & 9 & 3.45 & 1.26 \\
& & $28.6 \%$ & $23.2 \%$ & $16.6 \%$ & $28.2 \%$ & $3.5 \%$ & & \\
\hline 20 & Computer system & 61 & 85 & 41 & 50 & 22 & 3.44 & 1.27 \\
& & $23.6 \%$ & $32.8 \%$ & $15.8 \%$ & $19.3 \%$ & $8.5 \%$ & & \\
\hline 21 & Orthoscopic & 52 & 84 & 70 & 33 & 20 & 3.44 & 1.17 \\
& & $20.1 \%$ & $32.4 \%$ & $27.0 \%$ & $12.7 \%$ & $7.7 \%$ & & \\
\hline 22 & Electronic BP Gauge & 72 & 75 & 27 & 29 & 56 & 3.30 & 1.52 \\
& & $27.8 \%$ & $29.0 \%$ & $10.4 \%$ & $11.2 \%$ & $21.6 \%$ & \\
\hline
\end{tabular}

\section{Key: D=Daily, W= Weekly, M=Monthly, O=Occasionally, N=Never}

Table 3 shows thatECG machine $(\bar{x}=3.84)$ ranked highest by the mean score rating and was followed in succession by $\operatorname{VCD}(\bar{x}=3.82)$, Internet $(\bar{x}=3.79)$ and Teleconferencing $(\bar{x}=3.78)$. This implies that from the above result was that ECG machine, VCD, Internet, Teleconferencing, Telemedicine, Hemoglobin electrophoresis, GSM phones, Ipad, Ipod, Projectors, Videoconferencing, incubator, Video and DVD were the most frequently accessed health information resources for clinical decision making among medical doctors in the study. This study also showed the frequency of accessibility of health information resources for clinical decision making among medical doctors in OAUTH and the reason for this was because these were the items that ranked above the weighted mean of 3.62 set as the benchmark.It was also found out from the FGD that ECG machine, hemoglobin electrophoresis and DVD for clinical decision making was high

Table 4:The extent of use of various core skills of clinical decision making among medical doctors in OAUTH

\begin{tabular}{|c|c|c|c|c|c|c|c|}
\hline $\mathbf{S} / \mathbf{N}$ & Core skills of clinical decision making & HA & MA & RA & NA & $\bar{x}$ & S.D \\
\hline 1 & Pattern recognition from experience & $\begin{array}{l}111 \\
42.9 \%\end{array}$ & $\begin{array}{l}131 \\
50.6 \%\end{array}$ & $\begin{array}{l}5 \\
1.9 \%\end{array}$ & $\begin{array}{l}12 \\
4.6 \%\end{array}$ & 3.32 & 0.73 \\
\hline 2 & Critical thinking without emotion & $\begin{array}{l}86 \\
33.2 \%\end{array}$ & $\begin{array}{l}142 \\
54.8 \%\end{array}$ & $\begin{array}{l}18 \\
6.9 \%\end{array}$ & $\begin{array}{l}13 \\
5.0 \%\end{array}$ & 3.16 & 0.76 \\
\hline 3 & Hypothesis updating & $\begin{array}{l}87 \\
33.6 \%\end{array}$ & $\begin{array}{l}118 \\
45.6 \%\end{array}$ & $\begin{array}{l}40 \\
15.4 \%\end{array}$ & $\begin{array}{ll}14 \\
5.4 \%\end{array}$ & 3.07 & 0.84 \\
\hline 4 & Perception based confidence & $\begin{array}{ll}81 \\
31.3 \%\end{array}$ & $\begin{array}{l}117 \\
45.2 \%\end{array}$ & $\begin{array}{l}34 \\
13.1 \%\end{array}$ & $\begin{array}{l}27 \\
10.4 \%\end{array}$ & 2.97 & 0.93 \\
\hline 5 & Proactive decision making & $\begin{array}{l}72 \\
27.8 \%\end{array}$ & $\begin{array}{l}127 \\
49.0 \%\end{array}$ & $\begin{array}{l}37 \\
14.3 \%\end{array}$ & $\begin{array}{l}23 \\
8.9 \%\end{array}$ & 2.96 & 0.88 \\
\hline 6 & Overcoming environment task complexity & $\begin{array}{l}69 \\
26.6 \%\end{array}$ & $\begin{array}{l}129 \\
49.8 \%\end{array}$ & $\begin{array}{l}42 \\
16.2 \%\end{array}$ & $\begin{array}{l}19 \\
7.3 \%\end{array}$ & 2.96 & 0.85 \\
\hline 7 & $\begin{array}{llll}\begin{array}{l}\text { Teamwork } \\
\text { colleagues }\end{array} & & \text { gathered evidence } & \text { from } \\
\end{array}$ & $\begin{array}{ll}89 \\
34.4 \%\end{array}$ & $\begin{array}{l}100 \\
38.6 \%\end{array}$ & $\begin{array}{l}38 \\
14.7 \%\end{array}$ & $\begin{array}{l}32 \\
12.4 \%\end{array}$ & 2.95 & 0.99 \\
\hline 8 & Reflection using feedback from others & $\begin{array}{l}75 \\
29.0 \%\end{array}$ & $\begin{array}{l}121 \\
46.7 \% \\
\end{array}$ & $\begin{array}{l}35 \\
13.5 \%\end{array}$ & $\begin{array}{l}28 \\
10.8 \%\end{array}$ & 2.94 & 0.93 \\
\hline 9 & Age and educational level & $\begin{array}{l}81 \\
31.3 \%\end{array}$ & $\begin{array}{l}106 \\
40.9 \%\end{array}$ & $\begin{array}{l}46 \\
17.8 \%\end{array}$ & $\begin{array}{l}26 \\
10.0 \%\end{array}$ & 2.93 & 0.94 \\
\hline 10 & Communication skills from active listening & $\begin{array}{l}80 \\
30.9 \%\end{array}$ & $\begin{array}{l}106 \\
40.9 \%\end{array}$ & $\begin{array}{l}45 \\
17.4 \%\end{array}$ & $\begin{array}{l}28 \\
10.8 \%\end{array}$ & 2.92 & 0.95 \\
\hline 11 & Knowledge sharing among the professionals & $\begin{array}{l}82 \\
31.7 \%\end{array}$ & $\begin{array}{l}102 \\
39.4 \%\end{array}$ & $\begin{array}{l}45 \\
17.4 \%\end{array}$ & $\begin{array}{l}30 \\
11.6 \%\end{array}$ & 2.91 & 0.97 \\
\hline 12 & Time pressure balance & $\begin{array}{l}70 \\
27.0 \%\end{array}$ & $\begin{array}{l}111 \\
42.9 \%\end{array}$ & $\begin{array}{l}56 \\
21.6 \%\end{array}$ & $\begin{array}{l}22 \\
8.5 \%\end{array}$ & 2.88 & 0.90 \\
\hline 13 & Evidence-based approaches & $\begin{array}{l}72 \\
27.8 \%\end{array}$ & $\begin{array}{l}95 \\
36.7 \%\end{array}$ & $\begin{array}{l}688 \\
26.3 \%\end{array}$ & $\begin{array}{l}24 \\
9.3 \%\end{array}$ & 2.83 & 0.94 \\
\hline
\end{tabular}

KEY: HA=Highly Accessible, MA=Moderately Accessible, RA= Rarely Accessible, NH=Not Accessible 
Table 4 shows that Pattern recognition from experience $(\bar{x}=3.32)$ ranked highest by the mean score rating and was followed in succession by Critical thinking without emotion $(\bar{x}=3.16)$, Hypothesis updating $(\bar{x}=3.07)$ and Perception based confidence $(\bar{x}=2.97)$. This implies that from this using the weighted mean of 3.01 is that CT Scan, ECG machine, VCD, DVD, Autoclave, Glucometer, incubator, Hemoglobin electrophoresis and telemedicine were the most highly utilised health information resources for clinical decision making among medical doctors in OAUTH. Furthermore, the utilisation of various core skills of clinical decision making among medical doctors in OAUTH and also found out from the FGD that the major core skills a clinical professional should possess in making clinical decision include critical thinking without emotions and time pressure balance.

\section{Summary of the findings}

Based on the research questions answered, the hypotheses tested and focus group discussion in this study, the findings revealed that:

1. The CT Scan, ECG machine, Incubator, Orthoscopic, Radiograph, GSM phones, ipad, ipod, Microscope and Computer system were the major health information resources accessible for clinical decision making among medical doctors in the study

2. The level of accessibility to health information resources for clinical decision making among medical doctors in OAUTH was high.

3. The health information resources for clinical decision making are highly accessible.

4. The extent of use of health information resources for clinical decision making among the medical doctors in OAUTH was high and the pattern of use was on a weekly basis.

\section{Conclusion}

The CT Scan, ECG machine, incubator, orthoscopic, radiograph, GSM phones, ipad, ipod, microscope and computer system were the major health information resources accessible for clinical decision making among medical doctors in the study. The level of accessibility to health information resources for clinical decision making among Medical doctors in OAUTH was high. The health information resources for clinical decision making are highly accessible. The extent of use of health information resources for clinical decision making among Medical doctors in OAUTH is high and the pattern of use was on a weekly basis. The frequency of use of health information resources for clinical decision making was high also and the pattern of use was on a weekly basis. The extent of use of various core skills of clinical decision making among found by the study was to a very high extent.

\section{Recommendations}

Based on the findings of this study, the following recommendations were made:

i. Although the level of accessibility of health information resources for clinical decision making among medical doctors was high effort should be intensified to ensure that health information resources are more accessible to medical doctors

ii. The extent of use of health information resources for clinical decision making among medical doctors was reportedly high but there was still room for improvement among the medical doctors

iii. More attention should also be paid to the use of health information resources among the medical doctors as the pattern of usage could increase from weekly basis to either daily or by weekly basis

iv. Medical doctors should equip themselves through training, seminars, conferences and various capacity building programmes to improve on their core skills for CDM 


\section{References}

Aramide, K.O., Oduroye A. \&Alagbe A. (2012): Effect of Health Information Literacy on the Attitude of Women towards Family Planning

Aspinall S, Good C, Glassman P\& Valentino M (2008). The evolving use of cost-effectiveness analysis in formulary management within the Department of Veteran Affairs. Med Care (7 Supplement)II20 II 26.

Afolayan O. T. \&Oyekunle R. A. (2014). Availability, Accessibility and Frequency of Use ICT by health Professional in Florin, Metroplolis. Covenant Journal of Informatics and communication $\begin{array}{llllll}\text { technology } \mathrm{Vol} & 2(1) & \mathrm{pg} & 1-13 & \text { Retrieved from }\end{array}$ https://cujournals.convenantuniversity.edu.ng/index:php/syict/issue/view/13. On March 142019.

Aguolu, C.C.\&Aguolu, I .E(2002). Libraries and Information Management in Nigeria. Seminal Essays on Theme and Problems. Ed-Linform Service, Maiduguri Retrieved from https://www.scirp.org on January 192019.

Ali M, Talpur M H, Alamgir A \& javad MA (2015). OrganisationalInformation Theory a mechanism to ensure community participated: A case study of a Malaysian NGO. Nice Research Journal. Vol8 (31)Pg1-15

Attama R \&Ezema I (2005) Library and Information Service. A practical approach $2^{\text {nd }}$ ed. Enugu mikon press.

Chimmock P, Nandi A \& Clarke M (2005) is Evidence Based Medicine Relevant to the Developing World, Advance Access publication. Vol 2 (3) Pg 321-324 Retrieved from https:// doi:10.1093/ecam/neh114 on March 142019

Choudhry NK, Fletcher RH\&Soumerai R. (2005)SytematicReview: The relationship between clinical experience and quality of health care, Arin Intern medicine Vol101(142)Pg 260-273

Davies K. (2007) The Information- Seeking behavior: a review of the Evidence, Health Information and libraries Journal, Vol 13 Pg 78- 94 Retrieved from https://www.doi.10.111/J.14711842.2007.00713.4 on March 182019

Gans D, Kralweki J, Hammons T \& Dowd B (2005). Medical groups adoption of electronic health record and information system, Journal of health affairs Vol 25 (5) pg 1323 - 1333 retrieved from https://doi.org/10.1377/hlthaff.24-5.1323 on Feb 2019

Gatero G. (2010). Utilisation of ICT for Accessing Health Information by Medical Professionals in Kenya, Journal of Health Informatics in Developing CountriesVol 5(1) Pg 1-7 Retrieved from https://www.jhidc.org/index.php/jhldc/article/view/ss on March 142019

Jacobs W, Amuta A \&Jeon K (2017) Health Information seeking in the digital age, Journal of Health communication.Vol $3 \quad$ (1) $\quad \mathrm{Pg} \quad 232-247 \quad$ Retrieved from https:// doi.org//0.1080/10410236.2014.9799.76 on May 172019

Kahane S. (2011) must appear to be all known patients and family physicians perspectives on information seeking during consultation can form physicians Vol $57 \mathrm{pg} 2778$ - 236 Retrieved from https://www.ncb.nlm.nih.gov/pmc/articles on March 22019

Nuq P (2012). Toward a better understanding of the intention to use health service by medical professional, 
the case of developing coutries $\mathrm{PhD}$ thesis submitted to the school of management. University of Nestle.

Oltman S.M (2009). Information Access Indianna University, Springer. Retrieved from https://bpm.ils.indiana.edu on March 162019

Panahi S. (2014) Social Media and tacit knowledge sharing: physicians' perspectives and experiencesPhd thesis submitted to the department of information system school, Queens and Universally.

Sketcher (2017). Guide to informed decision making in health care. Journal of state of Queens health, $2^{\text {nd }}$ edition. P 8 - 12. Retrieved from https://creative common.org/licenses/by-nc/2.5/au/ on May 17, 2019.

Van Osch S, Wakker P, van den Hout\&Stiggelbout A (2004). Correcting biases in standard gamble and time tradeoff utilities. Medical Decision Making;24(511-517)

Yogarajan V, Mayo M \&Pfahringer B (2018). Privacy Protection for Health information Research in New Zealand District Health Boards Journal of New Zealand Medical Association 131 (1485) Pg 19-26. Retrieved from researchcommons.waikato.ac.nz April 162019 